\title{
Aurèlie Journo (dir.), Nairobi: urbanités contemporaines
}

\section{Claudia Mansueto}

\section{Q OpenEdition \\ 1 Journals}

\section{Edizione digitale}

URL: http://journals.openedition.org/studifrancesi/3895

DOI: 10.4000/studifrancesi.3895

ISSN: 2421-5856

\section{Editore}

Rosenberg \& Sellier

\section{Edizione cartacea}

Data di pubblicazione: 1 décembre 2012

Paginazione: 619-620

ISSN: 0039-2944

\section{Notizia bibliografica digitale}

Claudia Mansueto, «Aurèlie Journo (dir.), Nairobi: urbanités contemporaines», Studi Francesi [Online], 168 (LVI | III) | 2012, online dal 30 novembre 2015, consultato il 06 mars 2021. URL: http:// journals.openedition.org/studifrancesi/3895 ; DOI: https://doi.org/10.4000/studifrancesi.3895

Questo documento è stato generato automaticamente il 6 mars 2021.

\section{(c) (i) (9)}

Studi Francesi è distribuita con Licenza Creative Commons Attribuzione - Non commerciale - Non opere derivate 4.0 Internazionale. 


\title{
Aurèlie Journo (dir.), Nairobi: urbanités contemporaines
}

\author{
Claudia Mansueto
}

\section{NOTIZIA}

AURÈLIE JOURNO (dir.), Nairobi: urbanités contemporaines, «Études littéraires africaines», n. 31, 2011, pp. 130.

1 Questo importante numero di «Études littéraires africaines» è dedicato all'analisi dell'emergente letteratura keniota. Al voluminoso dossier costituito dai cinque contributi di Aurélie Journo, Olivier mARCEL, Hervé MAUPEU, Colomba muRIUngi e di Sheila ALI RYANGA in collaborazione con Rachel WANGARI MAINA (pp. 5-68) si aggiungono un omaggio a Aimé Césaire (pp. 69-79) e una nutrita sezione di compte-rendus (pp. 83-125). L'obiettivo degli studiosi che hanno contribuito alla costituzione del dossier è sicuramente quello di introdurre il lettore alla conoscenza di una giovane letteratura in fieri: gli intellettuali kenioti citati, riuniti intorno alla rivista «Kwani?» (2003), interpretano le problematiche tipiche del loro territorio in un'ottica nuova: la prostituzione, nel saggio di Colomba MURIUNGI, diventa uno strumento «d'émancipation économique» (p.54); la città non è più vista come spazio fisico deturpato dal caos e dalla violenza, ma anche come luogo mentale «où on déchiffre la nature de la condition de l'homme kenyan» (p. 13); la classe media rivela, al di là dell'ostentato benessere, le sue nascoste contraddizioni, le sue paure.

Dalla lettura dei saggi che costituiscono il numero, si evince l'idea di una letteratura in fase embrionale, ancora in cerca di un'identità. Il desiderio di uscire dai canoni imposti durante il periodo coloniale sembra tradursi in uno spasmodico impeto paradossale che spinge ad interpretare gli annosi fardelli che pesano sullo sviluppo africano in modo sì originale, ma spesso anche superficiale. L'intellettuale Genga-Idowu, ad esempio, considera la mercificazione del corpo come una via di affermazione sociale, ma dimentica, come tra l'altro evidenzia Colomba Muriungi, tutte le problematiche 
sanitarie connesse all'esercizio della prostituzione. Lo spaccato letterario keniota che emerge dal dossier Nairobi: urbanités contemporaines è sicuramente apprezzabile perché mostra gli sforzi di una generazione di giovani intellettuali alla ricerca di una propria affermazione culturale ed identitaria, ma mostra anche tutta la difficoltà che incontrano questi promettenti scrittori nell'individuare un proprio percorso creativo maturo e consapevole. 